\title{
Seroprevalence of Infectious Markers in Blood Donors in Mbujimayi "Case of Kansele General Hospital” (Democratic Republic of Congo)
}

\author{
Kabambi Bukasa Valentin ${ }^{*}$, Kanyiki Katala Moise ${ }^{2}$, Kaseka Cisuaka Jeanne1, \\ Kayembe Meji Jean-Pierre ${ }^{3}$, Tshibanda Tshibanda Etienne, ${ }^{4}$ Mutombo Mutombo Albert², \\ Katuku Ciala Charles' ${ }^{2}$, Ciamala Mukendi Paul ${ }^{1}$, Ntumba Muamba Alidor ${ }^{2}$ \\ ${ }^{1}$ Mbuji-Mayi Higher Institute of Medical Techniques, Nursing, Nursing Education and Administration Option, Mbuji-Mayi, \\ Democratic Republic of Congo \\ ${ }^{2}$ Higher Institute of Medical Techniques of Mbuji-Mayi, Community Health Section, Epidemiology Option, Mbujimayi, \\ Democratic Republic of Congo \\ ${ }^{3}$ Higher Institute of Medical Techniques of Mbuji-Mayi, Laboratory Techniques Section, Mbuji-Mayi, \\ Democratic Republic of Congo \\ ${ }^{4}$ Higher Institute of Medical Techniques of Kalenda, Nursing Section, Hospital Option, Mbujimayi, \\ Democratic Republic of Congo \\ Email: *paultshamala@gmail.com
}

How to cite this paper: Valentin, K.B., Moise, K.K., Jeanne, K.C., Jean-Pierre, K.M., Etienne, T.T., Albert, M.M., Charles, K.C., Paul, C.M. and Alidor, N.M. (2019) Seroprevalence of Infectious Markers in Blood Donors in Mbujimayi "Case of Kansele General Hospital” (Democratic Republic of Congo). Open Access Library Journal, 6: e5901.

https://doi.org/10.4236/oalib.1105901

Received: November 4, 2019

Accepted: November 26, 2019

Published: November 29, 2019

Copyright $\odot 2019$ by author(s) and Open Access Library Inc.

This work is licensed under the Creative Commons Attribution International License (CC BY 4.0).

http://creativecommons.org/licenses/by/4.0/

(c) (i) Open Access

\begin{abstract}
Blood transfusion is a life-saving act because in some cases, it is the last resort to save an individual's life. However, the seroprevalence of infectious markers in blood donors is a major public health problem, both in developed and developing countries, in its magnitude. The purpose of this study was to determine the seroprevalence of infectious markers in blood donors. This is a descriptive study conducted in the city of Mbujimayi at kansele Hospital among registered blood donors (family volunteers and paid) from the period $12 / 01 / 2017$ to $13 / 01 / 2018$. The data were collected in a cross-sectional manner. The following observations were made: in the study period, 522 blood donors were registered. After analyzing the data, the seroprevalence of HIV/AIDS in blood donors is $4.4 \%, 2.1 \%$ of cases have an HCV serological status and $5.9 \%$ a HBS positive serological status, and $2.1 \%$ a positive RPR HIV status, the male sex predominated with $85.4 \%$ was male.
\end{abstract}

\section{Subject Areas}

Infectious Diseases

Keywords

Seroprevalence, Infectious Markers, Mbujimayi 


\section{Introduction}

Blood transfusion is an operation that involves injecting blood or its derivatives into an individual by intravenous infusion. According to the WHO, blood transfusion is a treatment indicated to partially and transiently compensate for the deficiency of one or more components of blood tissue that would affect the patient's survival [1].

Blood transfusion is a medical procedure, which aims to bring blood or its derivatives to the patient. It is the result of a complex chain of activities in which different categories of medical and paramedic personnel are involved, therefore it cannot be considered an innocuous act. It remains tainted by many risks, which can be, infectious, immunological, hemodynamic and metabolic.

In order to combat these risks, transfusion safety (the set of measures to eliminate the immunological and infectious risks associated with transfusion of blood products) has been defined by the WHO, which has further clarified the 3 components main: blood availability, blood safety and judicious use of labile blood products [2].

The transmission of infectious agents such as human immunodeficiency virus (HIV), viral hepatitis C (HCV), hepatitis B (HBS) and syphilis (RPR), poses a greater threat to the recipient's transfusion safety. Blood transfusion is characterized in the majority of sub-Saharan African countries by a high prevalence of infectious agents [3], a chronic shortage of blood in their blood pockets, and a lack of financial resources and skilled personnel.

In developing countries, many people die because of the lack of safe blood, even in some urban health facilities [4]. Blood transfusion saves lives and improves health, but millions of patients do not have timely access to safe blood due to a lack of reliable blood donors. Blood transfusions are an essential aspect of health care and everyone must have equitable access to uncontaminated blood [5].

In sub-Saharan Africa, two factors reflect the difficulties encountered in waiting for optimal transfusion safety, the existence in the population of a high frequency of various infections, some of which are transmitted by blood transfusion and the still insufficient proportion of volunteer donors who make up the safest group [6].

Because of its frequency and severity, the pathologies due to these 4 pathogens constitute a public health problem while blood transfusion is by far the main source of transmission of these agents especially HBV. In developed countries, the seroprevalence of HIV, HBV, HCV and T. pallidum among blood donors is $0.11 \%, 2.47 \%, 0.32 \%$ and $0.79 \%$ respectively [7]. Against $2 \%$ (HIV), $7.2 \%$ (HBV), $3.96 \%(\mathrm{HCV})$ and $0.70 \%(\mathrm{HCV}) \mathrm{T}$. pallidum) in developing countries [8].

As in other African countries, the Democratic Republic of Congo does not rule out this dangerous situation. The study conducted by Michel Kabamba et al. in 2012 entitled "Prevalence of Infectious Markers in Semi-Rural Blood Donors cases of Kamina Reference General Hospital", HIV seroprevalence in this study 
was $2.9 \%$ [9]. In addition, Batina A. et al., through their study of infectious markers in donors in the Democratic Republic of Congo, revealed that HIV prevalence was $4.7 \%$ in Kisangani and the northern Democratic Republic of Congo was 5.6\% [6]. For his part, Michel Kabamba et al. report an overall seroprevalence of $1.6 \%$ [9] of Hepatitis B among blood donors in rural Kamina (Democratic Republic of Congo). In another study, we the authors present a seroprevalence of hepatitis $\mathrm{C}$ of $0.2 \%$ and a seroprevalence of syphilis of $0.2 \%$. The seroprevalence of hepatitis B virus in blood donors is $1.6 \%$ to $8.01 \%$ : Lubumbashi 8.01\% [10], Moba 3.9\% [11] and Mbuji-Mayi 2.2\% [12].

\section{Materials and Methods}

The objective of this study is to contribute to improving the transfusion safety of blood products in Mbuji-Mayi by defining the prevalence and factors promoting the seroprevalence of infectious markers in blood donors Mbuji-Mayi and especially those of Kansele Hospital.

To carry out this study, we used the retrospective cross-sectional method using a preconceived data collection grid based on our study variables; we used the technique of documentary analysis. The study was conducted in a hospital setting, namely Kansele General Hospital, where data was collected using a data collection grid. The period of our research ranges from 12/01/2017 to 13/01/2018. That's a year. All donors who were received and registered at Kansele General Hospital during the period covered by this study are the target population of this study. This hospital is chosen for its high capacity. Sample and sampling: In this study we used the non-probabilistic sampling method. The total population of this study is estimated at 522. The epi info 3.5.1 software had been used as an analysis tool. The following static measures will be calculated: frequencies to summarize categorical variables, central trend and dispersion measures to summarize quantitative variables. This was essentially the average around its standard deviation as the data were normally distributed.

\section{Results}

The results of Table 1 show that $79.3 \%$ of donors were between 21 and 45 years of age, followed by those under or equal to 20 years of age (Table 1 ).

After analyzing these results we draw conclusions that $85.4 \%$ of donors were male versus $14.6 \%$ female (a sex ratio H/F of 6.1) (Table 2).

The most proportion of respondents in this study had a blood group $\mathrm{O}$ or $52.3 \%$ followed by those in group A with $24.7 \%$ and those in the $\mathrm{AB}$ group were last with $1.5 \%$ (Table 3).

These results show that $4.4 \%$ of the respondents in this study were HIV-positive (HIV/AIDS) (Table 4).

This study found that $2.1 \%$ of respondents had a positive HCV status (Table 5).

After analysing this figure, 5.9\% of respondents had a positive Hbs HIV status 


\section{(Table 6).}

Regarding the results of this study, $2.1 \%$ of respondents had a positive RPR status (Table 7).

Analysis of this graph shows that $52.7 \%$ had already donated blood more than once compared to $47.3 \%$ who were at their first donation (Table 8).

These results show that most donors in this study were familiar with $45.6 \%$, followed by paid donors with $41.9 \%$ (Table 9 ).

Table 1. Répartition des enquêtés selon l'âge.

\begin{tabular}{ccc}
\hline Age of Blood donors & Squad & Percentage \\
\hline Under or equal to 20 years & 57 & 10.9 \\
21 to 45 years & 414 & 79.3 \\
46 and over & 51 & 9.8 \\
Total & $\mathbf{5 2 2}$ & $\mathbf{1 0 0}$ \\
\hline
\end{tabular}

Table 2. Donor breakdown by sex.

\begin{tabular}{ccc}
\hline Donor & Squad & Percentage \\
\hline Male & 446 & 85.4 \\
Female & 72 & 14.6 \\
Total & $\mathbf{5 2 2}$ & $\mathbf{1 0 0}$ \\
\hline
\end{tabular}

Table 3. Distribution of donors by sex by blood group.

\begin{tabular}{ccc}
\hline Blood Group & Squad & Percentage \\
\hline A & 129 & 24.7 \\
AB & 8 & 1.5 \\
B & 112 & 21.5 \\
O & 273 & 52.3 \\
Total & $\mathbf{5 2 2}$ & 100 \\
\hline
\end{tabular}

Table 4. Breakdown of respondents by HIV/AIDS HIV/AIDS status of blood donors.

\begin{tabular}{ccc}
\hline Serological status & Squad & Percentage \\
\hline Positive & 23 & 4.4 \\
Négative & 499 & 95.6 \\
Total & $\mathbf{5 2 2}$ & $\mathbf{1 0 0}$ \\
\hline
\end{tabular}

Table 5. Breakdown of respondents by blood donor HCV serological status.

\begin{tabular}{ccc}
\hline Serological status & Squad & Percentage \\
\hline Positive & 11 & 2.1 \\
Négative & 511 & 97.9 \\
Total & $\mathbf{5 2 2}$ & 100 \\
\hline
\end{tabular}


Table 6. Breakdown of respondents according to the Hbs Serological Status of Blood Donors.

\begin{tabular}{ccc}
\hline Serological status & Squad & Percentage \\
\hline Positive & 31 & 5.9 \\
Négative & 491 & 94.1 \\
Total & $\mathbf{5 2 2}$ & $\mathbf{1 0 0}$ \\
\hline
\end{tabular}

Table 7. Breakdown of respondents by blood donor RPR serological status.

\begin{tabular}{ccc}
\hline Serological status & Squad & Percentage \\
\hline Positive & 11 & 2.1 \\
Négative & 511 & 97.9 \\
Total & $\mathbf{5 2 2}$ & $\mathbf{1 0 0}$ \\
\hline
\end{tabular}

Table 8. Breakdown of respondents by number of donations already donated.

\begin{tabular}{ccc}
\hline Number of donations & Squad & Percentage \\
\hline Once & 247 & 47.3 \\
Twice and over & 275 & 52.7 \\
Total & $\mathbf{5 2 2}$ & $\mathbf{1 0 0}$ \\
\hline
\end{tabular}

Table 9. Breakdown of respondents by donor categories.

\begin{tabular}{ccc}
\hline Donor Categories & Squad & Percentage \\
\hline Volunteer & 66 & 12.6 \\
Family & 238 & 45.6 \\
Paid & 218 & 41.8 \\
Total & $\mathbf{5 2 2}$ & $\mathbf{1 0 0}$ \\
\hline
\end{tabular}

\section{Discussion}

After analysing our results, we found that $85.4 \%$ of our respondents were male versus $14.6 \%$ female. These results corroborate those of [13] who had shown that the majority of donors in his study were male, $94.4 \%$ and $5.6 \%$ female. These results are consistent with Tagny C.T. et al.'s observation that one of the common characteristics of blood donors in sub-Saharan Africa is the predominance of young male adults. The low proportion of women among blood donors is explained by numerous contraindications to blood donation including, among others, gestation, anemia, menstruation, breastfeeding, etc. [14].

These results show that the prevalence of HIV among donors was $4.4 \%$. After extensive analysis, we find that HIV/AIDS prevalence was high among young blood donors under the age of 21 , or $10.5 \%$, compared to $3.4 \%$ among those aged 21 to 45 and $7.8 \%$ among those over 45 years of age. The same is true for donors who were at their first donation with $8.5 \%$. This prevalence was also higher among family donors with $8.0 \%$. It should be concluded that young do- 
nors who are at first donation and who are in the family donor category are a category at risk of HIV/AIDS transmission among donors.

This prevalence remains lower than that reported in the Nigerian literature by $10.6 \%$ [15]; 10.7\% in Ethiopia [16] but this seroprevalence of HIV AIDS among blood donors was higher than ghana's by $3.8 \%$ [17].

These results are far superior to other studies such as [18] where HIV prevalence has a tendency to decline over time. However, the prevalence of HIV found in this study is higher than that of some African countries, $2.21 \%$ for Burkina Faso [8], 2\% for Tanzania [19]; Eritrea [20] and northern India [21] where seroprevalence is $0.11 \%, 0.24 \%$ respectively.

This study found that $2.1 \%$ of respondents had the seroprevalence of Anti-HCV antibodies. This study shows that the association between certain characteristics of the respondents and the serological status of HCV was related only with the number of donations, those who were at their first donation had a seroprevalence of $\mathrm{HCV}$ of $4.5 \%$ while it was zero in donors who were at their second and more donation. These results are lower than J.M.'s Kabinda, et al. which shows that the analysis of the seroprevalence of HCV antibodies in its study was 3.8\% [2] while it was in Central Africa at 3.6\%, Angola it was $5.7 \%$ and Chad at $4.8 \%$ [22]. But it joins the average rate of hepatitis $\mathrm{C}$ in low-resource countries [23].

This study also found that $5.9 \%$ of respondents had a seroprevalence of $\mathrm{Hbs}$ positive, the risk factor for $\mathrm{HBV}$ is that the prevalence of HBV was high in first-time donors (first donation) than in those who were at their second and more donations. The first blood donation is a risk factor for the transmission of infectious agents so this category is a very important priority for deep investigations. Those results although higher than those found by Michelle R. et al. by $4.2 \%$ [23], but this study showed that this prevalence tended to rise over the years.

The seroprevalence of hepatitis B, found in other studies, is lower than ours, such as that of Mulubwa Kyalubile et al. who had shown a prevalence of 3.9\% [13]; which was within the range of seroprevalences reported by studies in our country [2] [10] [11] [12] but far higher than that found by Kabamba Nzaji et al. in Lubumbashi (Michel et al., 2015).

Our results are also far below the rate found in some countries such as Nigeria (18.6\%), Guinea Bissau (16.2\%), Burkina Faso (14.96\%). This can be explained by the simple fact that there is no HBV vaccination policy in our communities.

This study also showed that the most proportion of donors were family with $45.6 \%$, followed by voluntary donors with $41.9 \%$. These observations have also been noted in other studies. One example was Mulubwa Kyalubile et al., which reported that family donors were predominant with $65.95 \%$ and $0.02 \%$ of paying donors [10].

Indeed, several previous studies around the world have shown that replacement donors (volunteers) are curiously paramount. In the study conducted by Singh et al., $82.4 \%$ were replacement donors [19], 94.7\% [9] in the Kakkar, N. et 
al. study while Sange and A. Pahuja et al. found 99.48\% [17]. At the Provincial Centre for Blood Transfusion in Katanga Province, the trends seem to be identical to our results [10] and also to those obtained by Noubiap in Cameroon [8]. This indicates that much needs to be done to motivate and bring voluntary donors together through awareness campaigns about the importance of blood donations, conditions necessary to hope to meet the goals that the World Health Organization has set for itself.

Most of the respondents in this study had an O blood type, followed by those in group $\mathrm{A}$ with $24.7 \%$ and those in the $\mathrm{AB}$ group were last with $1.5 \%$. We also noted that $79.3 \%$ of respondents were between 21 and 45 years of age, followed by those under or equal to 20 years of age.

\section{Conclusions}

Blood transfusion saves many lives during emergency medical care for people suffering from insufficiency in one or more constituents of the blood. Every recipient of the transfusion is exposed to the risk of accidents that may occur early or late. Transmission of infectious agents such as human immunodeficiency virus (HIV), hepatitis C (HCV), hepatitis B (HCB) and syphilis poses a greater threat to the recipient's transfusion safety.

At the end of our study, we note that overall seroprevalences in blood donors at Mbujimayi were $4.4 \%$ respectively for anti-HIV antibodies; $5.9 \%$ for the anti-HBs antigen; $2.1 \%$ for HCV antibodies and syphilis-directed antibodies. Blood donors between the ages of 21 and 45 and male had HBS, HCV and HVB seroprevalence higher than other donors. Most donors with high seroprevalence were family donors who were at their first blood donation.

The seroprevalence of HBV was high among donors at first donation: 10.9\% and $1.5 \%$ to those who were in their second and more donations. The family donor category had a seroprevalence of $8.8 \%$, compared to $3.7 \%$ among voluntary donors and $3.1 \%$ among paying donors. Those who were at their first donation had a seroprevalence of $\mathrm{HCV}$ of $4.5 \%$ while it was zero among donors who were at their second and more donations.

HIV/AIDS prevalence was high among young blood donors under 21 years of age, compared to $3.4 \%$ among those aged 21 to 45 and $7.8 \%$ among those over 45. The same is true for donors who were at their first donation with $8.5 \%$. This prevalence was also higher among family donors with $8.0 \%$. It should be concluded that young donors who are at first donation and who are in the family donor category are a category at risk of HIV/AIDS transmission among donors.

The prevalence of these different infectious markers in our environment demonstrates that transfusion remains a major public health problem in countries that sends development in general and to Mbujimayi in particular and justifies systematic screening blood donors in the end to reduce the risk of transfusion.

\section{Conflicts of Interest}

The authors declare no conflicts of interest regarding the publication of this paper. 


\section{References}

[1] Rakotoniaina, A.I., Randriamanantany, Z.A., Ranaivosoa, K.H.M., Andriambelo, V., Fortuné, H., Rakoto Alson, O.A. and Rasamindrakotroka, A. (2013) Seroprevalence of HIV, HBV, HCV and Treponema Blood Donors among Blood Sat Transfusion Antananarivo from 1992 to 2010.

[2] Batina, A., Kabemba, S. and Malengela, R. (2007) Infectious Markers among Blood Donors in Democratic Republic of Congo. Revue Médicale de Bruxelles, 28, 145-149.

[3] Bihl, F., Castelli, D., Marincola, F., et al. (2007) Transfusion Transmitted-Infections. Journal of Translational Medicine, 5, Article No. 25. https://doi.org/10.1186/1479-5876-5-25

[4] Choudhury, N. (2010) Transfusion Transmitted Infections: How Many More? Asian Journal of Transfusion Science, 4, 71-72. https://doi.org/10.4103/0973-6247.67017

[5] Kakisingi, C.N., Mukuku, O., Matanda, S.K., Manika, M.M., Kyabu, V.K., Kasamba, E.I., Mawaw, P.M., Mwamba, C.M. and Kapend, L. (2016) Epidemiological Profile and Seroprevalence of Blood Donors at the University Clinics in Lubumbashi, Democratic Republic of Congo. The Pan African Medical Journal, 23, 175. https://doi.org/10.11604/pamj.2016.23.175.8480

[6] Dhingra, N. and Hafner, V. (2006) International Transfusion Safety: The Role of WHO. Transfusion Clinique et Biologique, 13, 200-202. https://doi.org/10.1016/j.tracli.2006.07.007

[7] Elira-Dokekias, A., Okandze-Elenga, J.P., Dzia-Lepfoundzou, A. and Parra, H.J. (2002) Prevalence of Major Viral Markers among Blood Donors in Brazza Ville. Gas Transfus, 4-6.

[8] Jacques, J., Noubiap, N., Yvonne, W., Joko, A., Richie, J., Nansseu, N. and Gae, U. (2013) Sero-Epidemiology of Human Immunodeficiency Virus, Hepatitis B and C Viruses, and Syphilis Infections among First-Time Blood Donors in Edéa, Cameroon. International Journal of Infectious Diseases, 17, 832-837.

https://doi.org/10.1016/j.ijid.2012.12.007

[9] Kakkar, N., Kaur, R. and Dhanoa, J. (2004) Voluntary Donors-Need for a Second Look. Indian Journal of Pathology and Microbiology, 47, 381-383.

[10] Mark, E., Brecher and Hay, S.N. (2005) Bacterial Contamination of Blood Components. Clinical Microbiology Reviews, 18, 195-204. https://doi.org/10.1128/CMR.18.1.195-204.2005

[11] Mavenyengwa, R.T., Mukesi, M. and Chipare, I. (2014) Prevalence of Human Immunodeficiency Virus, Syphilis, Hepatitis B and C in Blood Donations in Namibia. BMC Public Health, 14, Article No. 424. https://doi.org/10.1186/1471-2458-14-424

[12] Mecky, I.N.M., Pius, M.M. and Eligius, F.L. (2006) Seroprevalence of Human Immunodeficiency Virus, Hepatitis B and C Viruses and Syphilis Infections among Blood Donors at the Muhimbili National Hospital in Dar Es Salaam, Tanzania. BMC Public Health, 6, Article No. 21. https://doi.org/10.1186/1471-2458-6-21

[13] Nononmulubwa, M.K.N., et al. (2017) Seroprevalence of Hepatitis b and in Blood Donor a kolwezi, EN DR Congo.

[14] Rotermann, M., Langlois, K., Andonov, A. and Trubnikov, M. (2011) Seroprevalence of Hepatitis B and Hepatitis C Virus Infections: Results from the Canadian Health Measures Survey, 2007 to 2009 and 2009 to 2011. Health Reports, 24, 3-13.

[15] Mulumba Mwamba, L.K. (2016) Seroprevalence and Epidemiological Profile of 
Blood Donors at the Lubumbashi University Clinics, Democratic Republic. Pan African Medical Journal, 23, 1-9. https://doi.org/10.11604/pamj.2016.23.175.8480

[16] Nagalo, M.B., Sanou, M., Bisseye, C., et al. (2011) Seroprevalence of Human Immunodeficiency Virus, Hepatitis B and C Viruses and Syphilis among Blood Donors in Koudougou (Burkina Faso) in 2009. Blood Transfusion, 9, 419-424.

[17] Pahuja, S., Sharma, M., Baitha, B. and Jain, M. (2007) Prevalence and Trends of Markers of Hepatitis C Virus, Hepatitis B Virus and Human Immunodeficiency Virus in Delhi Blood Donors: A Hospital Based Study. Japanese Journal of Infectious Diseases, 215, 389-391.

[18] Paul, C.M., Moise, K.K., Blood, B.N.D., Kennedy, N.M., Réne, J.M.M., Alain, K.K., Brigitte, K.T., Lubemba, G.M., Laurent, B.L. and Michel, K.N. (2017) Seroprevalence of Hepatitis B among Blood Donors in Mbuji-Mayi, "Case of Dipumba General Hospital” (DRC). Open Access Library Journal, 4, e3503. https://doi.org/10.4236/oalib.1103503

[19] Singh, B., Verma, M., Kotru, M., et al. (2005) Prevalence of HIV and VDRL Seropositivity in Blood Donors of Delhi. Indian Journal of Medical Research, 122, 234-236.

[20] Fessehaye, N., Naik, D. and Fessehaye, T. (2011) Transfusion Transmitted Infections. A Retrospective Analysis from the National Blood Transfusion Service in Eritrea. Pan African Medical Journal, 9, 40. https://doi.org/10.4314/pamj.v9i1.71219

[21] Makroo, R.N., Chowdhry, M., Bhatia, A., et al. (2011) Prevalence of HIV among Blood Donors in a Tertiary Care Centre of North India. Indian Journal of Medical Research, 134, 950-953. https://doi.org/10.4103/0971-5916.92640

[22] Dhingra, N. and Hafner, V. (2006) Safety of Blood Transfusion at the International Level. The Role of WHO. Transfusion Clinique et Biologique, 13, 200-202. https://doi.org/10.1016/j.tracli.2006.07.007

[23] Rotermann, M., Langlois, K., Andonov, A. and Trubnikov, M. (2011) Séroprévalence des infections par le virus de l'hépatite B et par le virus de l'hépatite C: Résultats de l'Enquête canadienne sur les mesures de la santé, 2007 à 2009 et 2009 à 2011. 